\title{
The Consensus $N$-Myristoylation Motif of a Geminivirus AC4 Protein Is Required for Membrane Binding and Pathogenicity
}

\author{
Vincent N. Fondong, ${ }^{1}$ R. V. Chowda Reddy, ${ }^{1}$ Cheng Lu, ${ }^{2}$ Bertrand Hankoua, ${ }^{1}$ Christian Felton, ${ }^{1}$ \\ Kirk Czymmek, ${ }^{2}$ and Fidelis Achenjang ${ }^{3}$ \\ ${ }_{1}$ Department of Biological Sciences, Delaware State University, 1200 North DuPont Highway, Dover, DE 19901, U.S.A.; \\ ${ }_{2}$ Delaware Biotechnology Institute, Delaware Technology Park, 15 Innovation Way, Newark DE 19711, U.S.A.; ${ }^{3}$ Union \\ College, 310 College Street, Barbourville, KY 40906, U.S.A.
}

Submitted 13 October 2006. Accepted 13 November 2006.

\begin{abstract}
Some geminiviruses encode a small protein, AC4, whose role in pathogenesis has only recently attracted attention. A few studies have shown that this protein is involved in pathogenesis and suppresses RNA silencing. Here, using Nicotiana benthamiana, we show that East African cassava mosaic Cameroon virus (EACMCV) AC4 is a pathogenicity determinant and that it suppresses the systemic phase of RNA silencing. Furthermore, confocal imaging analyses show that it binds preferentially to the plasma membrane as well as to cytosolic membranes including the perinucleus but is excluded from the nucleus. A computational examination of the AC4 protein encoded by the EACMCV, a bipartite geminivirus, shows that it encodes a consensus $N$-myristoylation motif and is likely posttranslationally myristoylated and palmitoylated. Replacement of Gly-2 and Cys-3 (sites of posttranslational attachment of myristic and palmatic acids, respectively) with alanine affected AC4 membrane binding and pathogenesis. Furthermore, replacement of Ile-5, a nonessential myristoylation residue, with alanine did not affect $\mathrm{AC} 4$ function. Together, these data indicate that EACMCV AC4 is likely dually acylated at Gly-2 and Cys-3 and that these modifications are intrinsic signals for membrane targeting and pathogenesis. This is the first report of a membrane protein to be involved in pathogenesis and RNA silencing suppression.
\end{abstract}

Additional keywords: palmitoylation, RNA silencing suppression, subcellular localization.

Most plant viruses have a very small genome (12 kb or less) and encode very few proteins; yet to infect a host and cause a disease, these viruses must counter the defense deployed by the host. To metabolize, these viruses must depend heavily on host factors with which they interact. There is increasing evidence that most viral genes are multifunctional (Dolja 2003; Kim et al. 2004; Mallory et al. 2001; Te et al. 2005). Geminiviruses, for example, have a much smaller genome than most viruses. The Geminiviridae family is divided into four genera according to their genome organizations and biological properties (Fauquet et al. 2003). Their genomes are made up of one or two circular single-stranded DNA molecules, each ranging from 2.6 to $2.8 \mathrm{~kb}$ and packaged as minichromosomes (Pilartz and Jeske 1992).

Corresponding author: V. N. Fondong: Telephone: +1.302.857.7377; Fax: +1.302.857.6512; E-mail: vfondong@ desu.edu
East African cassava mosaic Cameroon virus (EACMCV) belongs to the genus Begomovirus and was isolated from cassava (Manihot esculenta) in Cameroon and is associated with a growing epidemic in that country (Fondong et al. 2000). Like other bipartite begomoviruses, it has two genomic components, DNAA and DNA-B (Fig. 1A). DNA-A encodes six genes, two in the virus sense: $A V 1$, which codes for the coat protein $(\mathrm{CP})$, and $A V 2$, whose specific role has not been reported; four of the genes are in the complementary sense, including $A C 1$, which codes for replication-associated protein (Rep); $A C 2$ and $A C 3$, which code for the transcription protein and the replication enhancer protein, and AC4. DNA-B encodes two genes, BV1 and BC1, coding for the movement and the nuclear shuttle proteins, respectively. Because of their small size, some of these genes have been shown to play several roles during infection. It is only recently that the role of the AC4 protein in pathogenesis is attracting some attention. The fact that AC4 is wholly within the Rep (Fig. 1A) makes its study difficult. Also known as $\mathrm{C} 4$ in monopartite geminiviruses, AC4 appears to have divergent biological functions. For example, it was shown to play an important role in the infectivity of several bipartite geminiviruses (Elmer et al. 1988; Etessami et al. 1991; Hoogstraten et al. 1996; Pooma and Petty 1996; Sung and Coutts 1995). In contrast, disruption of the C4 open reading frame (ORF) of monopartite begomoviruses results in attenuated symptoms and low infectivity, suggesting that it is involved in either symptom development, virus movement, or both (Jupin et al. 1994; Rigden et al. 1994). Recently, Vanitharani and associates (2004) reported that African cassava mosaic virus (ACMV) AC4 suppresses posttranscriptional gene silencing (PTGS).

Geminiviruses are increasingly being used to study plant cell metabolism (Gutierrez 2000; Gutierrez et al. 2004), making an understanding of the role of their proteins in cell metabolism critical. A structural examination of the EACMCV AC4 protein and those of several other geminiviruses that infect a range of crops shows a conserved consensus $N$-myristoylation motif (Table 1). EACMCV AC4 can potentially attach two fatty acids including myristatic and palmitatic acids to Gly-2 and Cys-3, respectively, as predicted by several acylation algorithms (Bologna et al. 2006; Eisenhaber et al. 2003; Falquet et al. 2002; Maurer-Stroh et al. 2002, 2004; Podell and Gribskov 2004). Posttranslational myristoylation is the irreversible linkage of myristate to Gly-2 via an amide bond catalyzed by the enzyme $N$-myristoyl transferase (Podell and Gribskov 2004; Resh 1999), while palmitoylation is the reversible linkage of palmitate to variably located cysteine residues via a thioester 
bond subsequent to myristoylation. Although extensively studied in animal systems, plant protein myristoylation is only just gaining interest and has been confirmed in proteins involved in growth regulation, disease resistance, salt tolerance, and endocytosis. Examples of either predicted or biochemically identified myristoylated plant proteins include a calcium-binding protein required for salt tolerance (Ishitani et al. 2000) and calcium-dependent protein kinases from Arabidopsis thaliana, Oryza sativa, Lycopersicon esculentum, Cucurbita pepo, and Solanum tuberosum (Ellard-Ivey et al. 1999; Lu and Hrabak 2002; Martin and Busconi 2000; Raices et al. 2001; Rutschmann et al. 2002).

Here, we examine the role of the conserved amino-terminal consensus myristoylation and palmitoylation sites of the EACMCV AC4 protein in subcellular localization and pathogenesis. We show that membrane localization by AC4 is de- pendent on the putative $N$-myristoylation motif. We also show that this motif is required for AC4 to cause virus-like symptoms in Nicotiana benthamiana and suppress virus-induced gene silencing (VIGS).

\section{RESULTS}

\section{AC4 is a membrane-localizing protein.}

To examine the subcellular localization of AC4, we fused the sequence to the $\mathrm{N}$ terminus of synthesized (s) GFP (Chiu et al. 1996), thus obtaining AC4-GFP. AC4-GFP was transiently expressed under the control of the $35 \mathrm{~S}$ promoter in $N$. benthamiana plant leaves. The GFP fluorescence was observed with a confocal laser-scanning microscope. Still images suggested that AC4-GFP localizes with the plasma membrane (PM). Epidermal and mesophyl cells displayed a thin membrane-like

\section{A EACMCV genome organization}

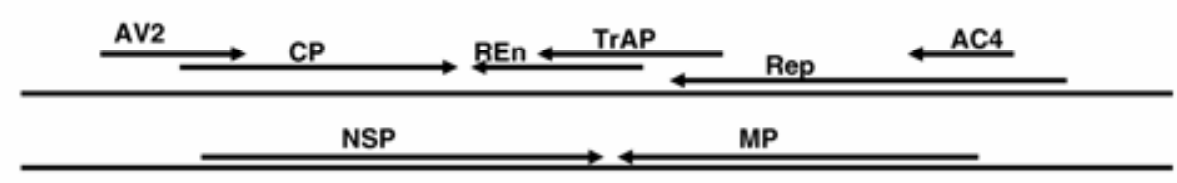

\section{B PVX expression}

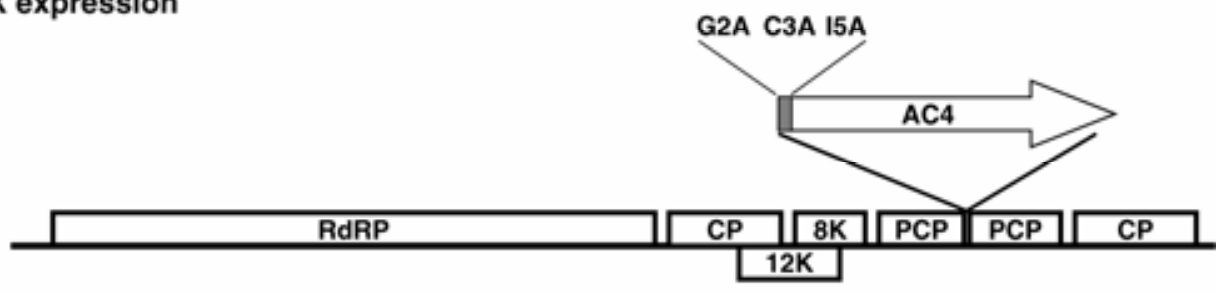

\section{C pEarleygate100 expression}

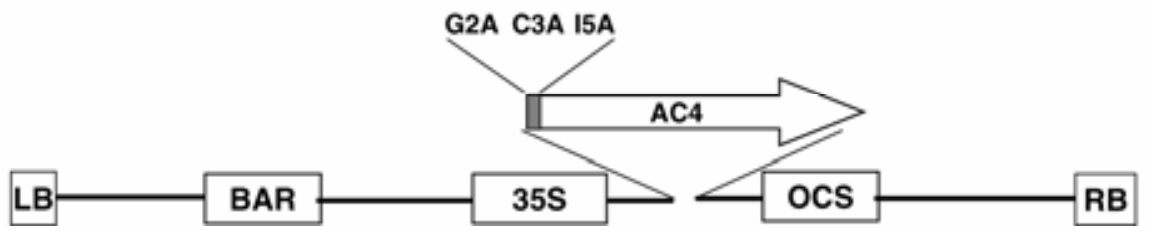

Fig. 1. A, Genome organization of East African cassava mosaic Cameroon virus. B, For expression in Nicotiana benthamiana, sequences of AC4 and mutants were inserted into the Potato virus $X$ vector (Chapman et al. 1992) and C, pEarleygate100 (Earley et al. 2006), using the in vitro site-specific procedure of Gateway Technology (Invitrogen).

Table 1. Consensus $N$-myristoylation motif sequences of selected virus and eukaryotic proteins

\begin{tabular}{|c|c|c|}
\hline Protein & Accession number & Sequence \\
\hline Consensus & & MGNLISTCSS SSKANTSARI \\
\hline East African cassava mosaic Cameroon virus AC4 & AF112354 & MGCLISMFSS NSKASSNVPT \\
\hline Sida mosaic Sinaloa virus AC4 & YP619889 & MGSLISTFSS SSKANTTARI \\
\hline Tomato golden mottle virus AC4 & ABF67530 & MGNLISMPLS NLKEKSRSRM \\
\hline Cotton leaf curl Bangalore virus $\mathrm{C} 4$ & YP277440 & MGNLIFTCSS SSKGSTSAKI \\
\hline Okra yellow mosaic Mexico virus AC4 & AAY27084 & MGNLICTSLS SSRGNTDARI \\
\hline Sweet potato leaf curl Georgia virus $\mathrm{C} 4$ & AAL69644 & MGLCTSMLSS SSRVKPNLKT \\
\hline Potato yellow mosaic Trinidad virus AC4 & AAC09257 & MGNLISTCLS SSKVNISARI \\
\hline Abutilon mosaic virus-HW C4 & AAB 18174 & MGSLISMCSY SSKANSNARI \\
\hline Foot-and-mouth disease virus - 3 Capsid & DQ009741 & MGAGQSSPAT GSQNQSGNTG \\
\hline Human immunodeficiency virus type $1 \mathrm{Gag}$ & AJ293865 & MGARASVLIG GKLNPWEKIR \\
\hline Type III effector protein avirulence protein avrB & AAA25726 & MGCVSSKSTT VLSPQTSFNE \\
\hline Calmodulin-domain protein kinase CDPK isoform 2 & AAF76372 & MGNACVGPNI SGNGFLQTVT \\
\hline Arabidopsis calcium dependent protein kinase & BAB08991 & MGNTCVGPSR NGFLQSVSAA \\
\hline Arabidopsis salt overly sensitive 3 & NM 122333 & MGCSVSKKKK KNAMRPPGYE \\
\hline
\end{tabular}


fluorescent band just beneath the cell wall (Fig. 2A and B). A high-magnification tangential optical section at the epidermal cell surface showed a continuous and somewhat heterogeneous pattern with small dark zones of exclusion (Fig. 2C). Bright punctate patterns were also observed as well as what appeared to be exclusion from microtubules closely appressed to the PM. Occasionally very weak nuclear localization was observed. PM localization by AC4-GFP contrasted with free GFP localization, which occurred in the nucleus as well as in the cytoplasm (Fig. 2D), and a high-magnification tangential optical section at the epidermal cell surface clearly showed cytoplasmic distribution with exclusion from some large organelles (Fig. 2E). To determine whether the GFP terminus to which AC4 was fused influenced membrane targeting, we translationally fused the AC4 to the carboxyl-terminus of the enhanced GFP to obtain GFP-AC4, which was also expressed in N. benthamiana. Unlike AC4-GFP, GFP-AC4 showed cytoplasmic distribution, occurring on the cell periphery and with prominent nuclear and cytoplasmic thread localization (Fig. 2F). A high-magnification tangential optical section at the epidermal cell surface clearly showed cytoplasmic distribution with exclusion from some large organelles (Fig. 2G).

\section{AC4 encodes a putative $N$-myristoylation motif.}

To determine whether AC4 is an intrinsic membrane-binding protein, we examined the AC4 sequence for membrane-localizing signals and identified a putative $\mathrm{N}$ terminal myristoylation motif predicted by several algorithms (Bologna et al. 2006; Eisenhaber et al. 2003; Falquet et al. 2002; MaurerStroh et al. 2002, 2004; Podell and Gribskov 2004). We then mutated the consensus $N$-myristoylation motif. Because Gly-2 is an absolute requirement for covalent attachment of the 14carbon myristate (Ishitani et al. 2000; Maurer-Stroh et al. 2004; Resh 1999), we replaced the Gly-2 residue with Ala to obtain the $\mathrm{AC} 4{ }^{\mathrm{G} 2 \mathrm{~A}}$ mutant. $\mathrm{AC} 4{ }^{\mathrm{G} 2 \mathrm{~A}}$ was translationally fused to the $\mathrm{N}$ terminus of sGFP and was expressed in $N$. benthamiana. Unlike AC4-GFP, AC4 ${ }^{\mathrm{G} 2 \mathrm{~A}}$-GFP showed a complete exclusion from the PM and appeared to target the chloroplast, as indicated by a three-dimensional confocal image (Fig. $2 \mathrm{H}$ and I). Apparent chloroplast targeting by $\mathrm{AC} 4^{\mathrm{G} 2 \mathrm{~A}}-\mathrm{GFP}$ was supported by structural similarities between its $\mathrm{N}$-terminal sequences of $\mathrm{AC} 4^{\mathrm{G} 2 \mathrm{~A}}$-GFP and chloroplast-targeting proteins (MAXSXMX SS) (von Heinjne et al. 1989). Contrary to AC4 ${ }^{\mathrm{G} 2 \mathrm{~A}}-\mathrm{GFP}$, GFP$\mathrm{AC} 4^{\mathrm{G} 2 \mathrm{~A}}$ exhibited periphery and nuclear localization (Fig. 2J). A high-magnification tangential optical section at the epidermal cell surface of GFP-AC4 ${ }^{\mathrm{G} 2 \mathrm{~A}}$-inoculated leaf tissues showed that the green fluorescence was in the cytoplasm but excluded from some large organelles (Fig. 2K).

To efficiently bind to the PM, myristoylated proteins require an additional membrane-binding signal. This second signal can either be a polybasic cluster or at least one Cys residue, espe- cially Cys-3, to which a second acylate, the 16-carbon palmitate, is attached. The $\mathrm{N}$ terminus of EACMCV encoded AC4 does not contain basic residues but contains Cys-3. To investigate whether Cys-3 plays a role in membrane targeting, we replaced it with Ala to obtain the $\mathrm{AC} 4{ }^{\mathrm{C} 3 \mathrm{~A}}$ mutant. Observation of epidermal leaf tissues inoculated with $\mathrm{AC} 4^{\mathrm{C} 3 \mathrm{~A}}-\mathrm{GFP}$ showed fluorescence along the cell periphery with strong perinuclear labeling (Fig. 2L). However, the intensity of green fluorescence on the periphery of cells expressing $\mathrm{AC} 4^{\mathrm{C} 3 \mathrm{~A}}-\mathrm{GFP}$ was lower than that observed in cells expressing AC4-GFP. A highmagnification tangential optical section at the epidermal cell surface showed an endoplasmic reticulum (ER)-like punctate web along the cell periphery with a faint granular appearance between the strands of the web (Fig. 2M). Mesophyl cells also exhibited a similar ER-like pattern with perinuclear labeling (Fig. 2N) and, at high magnification, a similar pattern of labeling as in epidermal cells was observed, with an ER-like web and faint granular fluorescence between strands of the web (Fig. 2N and $\mathrm{O}$ ).

Since the fifth amino-acid residue of the myristoylation signal is dispensable for $N$-myristoylation and membrane binding (Resh 1999), we continued our investigation of the AC4 consensus myristoylation signal by replacing Ile-5 with Ala $\left(\mathrm{AC} 4^{\mathrm{ISA}}\right) . A C 4^{15 \mathrm{~A}}$ was then fused to the $\mathrm{N}$ terminus of $\mathrm{sGFP}$ (AC4 $\left.4^{\mathrm{I} A}-\mathrm{GFP}\right)$. Similar to AC4-GFP, AC4 $4^{\mathrm{I5A}}-\mathrm{GFP}$ showed a membrane-like thin fluorescent band just beneath the cell wall in median epidermal cell optical sections (Fig. 2P). Unlike cytoplasmic labeling patterns, nuclear localization and cytoplasmic threads were never observed with $\mathrm{AC} 4^{\mathrm{I5A}}$-GFP. A highmagnification tangential optical section at the epidermal cell surface showed a continuous and somewhat heterogeneous pattern with small dark zones of exclusion and what appeared to be exclusion from microtubules closely appressed to the PM (Fig. 2Q).

\section{Gly-2 is required for $\mathrm{AC4}$ pathogenesis in N. benthamiana.}

To investigate the pathogenicity of AC4, we used the Potato virus $X$ (PVX) vector (Chapman et al. 1992) and the 35S promoter for expression in $N$. benthamiana. The AC4 ORF was cloned into the PVX and pEarleygate 100 vectors, both of which were transformed into Agrobacterium tumefaciens (strain GV3101). Agrobacterium cultures were infiltrated into plants at the five- to seven-leaf stage. Plants were placed in a growth chamber with $16 \mathrm{~h}$ of light $\left(\right.$ at $22^{\circ} \mathrm{C}$ ) and $8 \mathrm{~h}$ of darkness (at $18^{\circ} \mathrm{C}$ ). Plants inoculated with PVX alone showed no apparent symptoms (Fig. 3Aa). In contrast, plants inoculated with PVX-AC4 displayed typical virus-like symptoms in systemically infected leaves. These symptoms included mosaic, curling, folding, distortion with dark-green islands, and size reduction; veins showed a chlorotic aspect, while stems and petioles exhibited epinasty (Fig. 3Ab).

Fig. 2. Subcellular localization of East African cassava mosaic Cameroon virus-encoded AC4 protein and mutants using the synthetic green fluorescent protein (sGFP) (Chiu et al., 1996) in Nicotiana benthamiana leaf tissues. A, Epidermal cell localization of AC4-GFP (green) showed a thin membrane-like fluorescent band just beneath the cell wall (arrows). B, Mesophyl cells showing a thin fluorescent band adjacent to the cell wall. C, A high-magnification tangential optical section at the epidermal cell surface of AC4-GFP showing a heterogeneous pattern with small dark zones of exclusion (arrow). Insert,. Bright punctate patterns that were sometimes observed (asterisk) and plasma membrane (arrowheads). D and E, Cytoplasmic localization of free GFP (arrow indicates cytoplasmic threads). F and G, GFP-AC4 showed cytoplasmic distribution with prominent nuclear (arrow) localization and cytoplasmic threads (arrowheads). H and I, AC4 ${ }^{\mathrm{G} 2 \mathrm{~A}}$-GFP showing apparent chloroplast localization. $\mathbf{J}$ and $\mathbf{K}$, GFP-AC4 ${ }^{\mathrm{G} 2 \mathrm{~A}}$ showing cytoplasmic distribution. $\mathbf{L}$ to $\mathbf{O}$, Localization of AC4 $4^{\mathrm{C} 3 \mathrm{~A}}-\mathrm{GFP}$. L, Epidermal cell localization of AC4 ${ }^{\mathrm{C} 3 \mathrm{~A}}$-GFP with strong perinuclear labeling (arrow). M, A high-magnification tangential optical section at the epidermal cell surface showing an endoplasmic reticulum (ER)-like punctate web along the cell periphery (arrows) with a faint granular appearance between the strands of the web (asterick). $\mathbf{N}$ and $\mathbf{O}$, Mesophyl cells also exhibited a similar ER-like pattern with perinuclear labeling (arrow) and large aggregates (arrowheads) and faint granular fluorescence between the web (asterick). P, Localization of AC4 ${ }^{15 \mathrm{~A}}$-GFP showed a membrane-like thin fluorescent band just beneath the cell wall (arrows) in median epidermal cell optical sections. Q, A high-magnification tangential optical section at the epidermal cell surface of $\mathrm{AC} 4^{\mathrm{ISA}}$-GFP labeled tissue showed a continuous and somewhat heterogeneous pattern with small dark zones of exclusion (arrows) and what appeared to be exclusion from microtubules closely appressed to the plasma membrane (arrowheads). Scale bars $=20$ microns, except for $\mathrm{C}$ and $\mathrm{O}$ (scale $=10$ microns) and insert (scale $=5$ microns). 

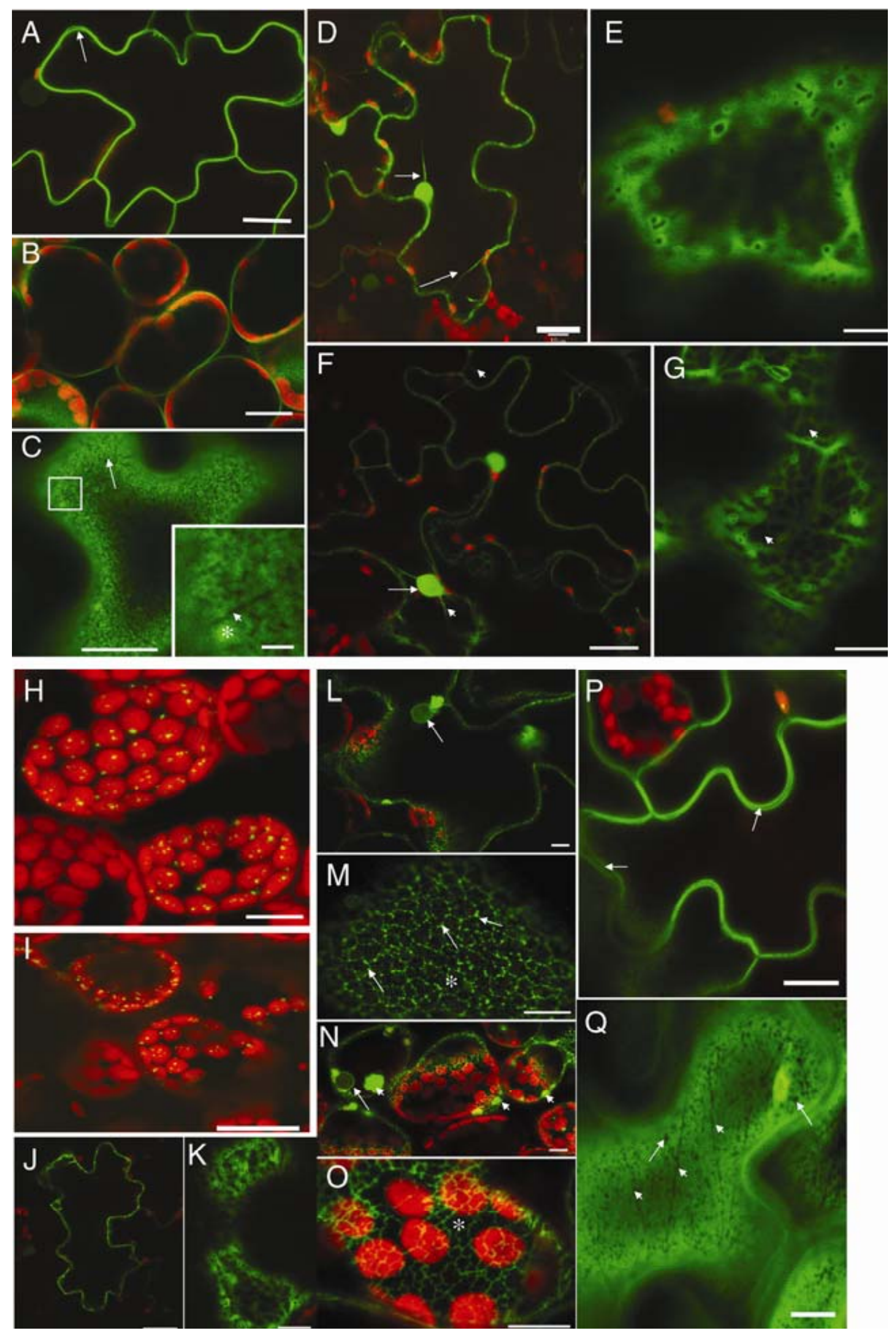
A possible role for the consensus $N$-myristoylation motif in pathogenicity was examined. The three AC4 mutants described above were expressed from the PVX vector (Fig. 1B) in $N$. benthamiana, and symptoms produced were compared with symptoms caused by PVX-AC4. Results showed that PVX-
$\mathrm{AC} 4^{\mathrm{C} 3 \mathrm{~A}}$ and PVX-AC4 ${ }^{\mathrm{ISA}}$ induced symptoms similar to symptoms induced by PVX-AC4 (Fig. 3Ad and e) although symptoms elicited by $\mathrm{PVX}-\mathrm{AC} 4^{\mathrm{C} 3 \mathrm{~A}}$ generally appeared two to three days later. In contrast, $\mathrm{PVX}-\mathrm{AC} 4{ }^{\mathrm{G} 2 \mathrm{~A}}$ induced no apparent symptoms (Fig. 3Ac). Typical symptoms on leaves are shown

A
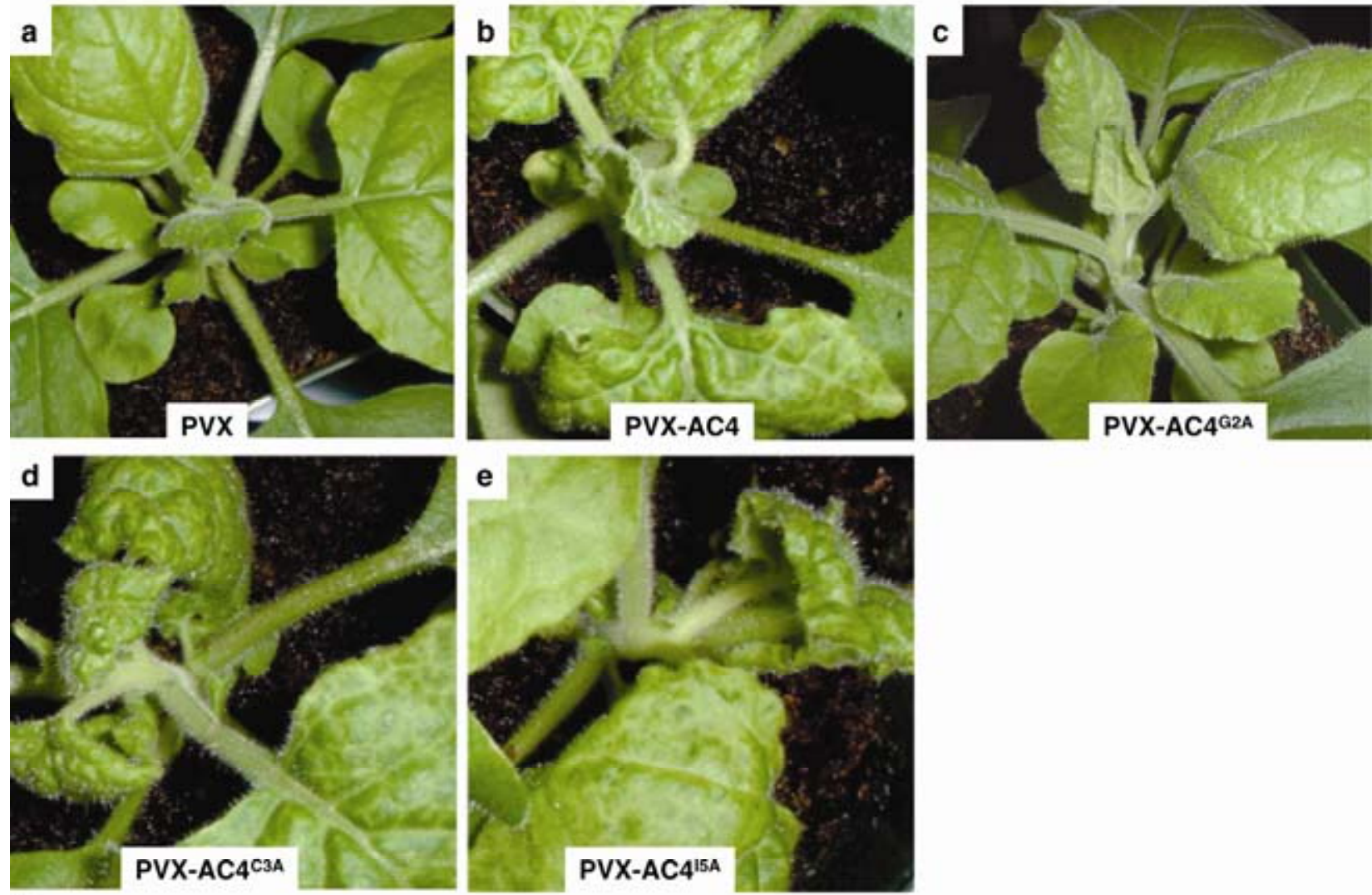

B
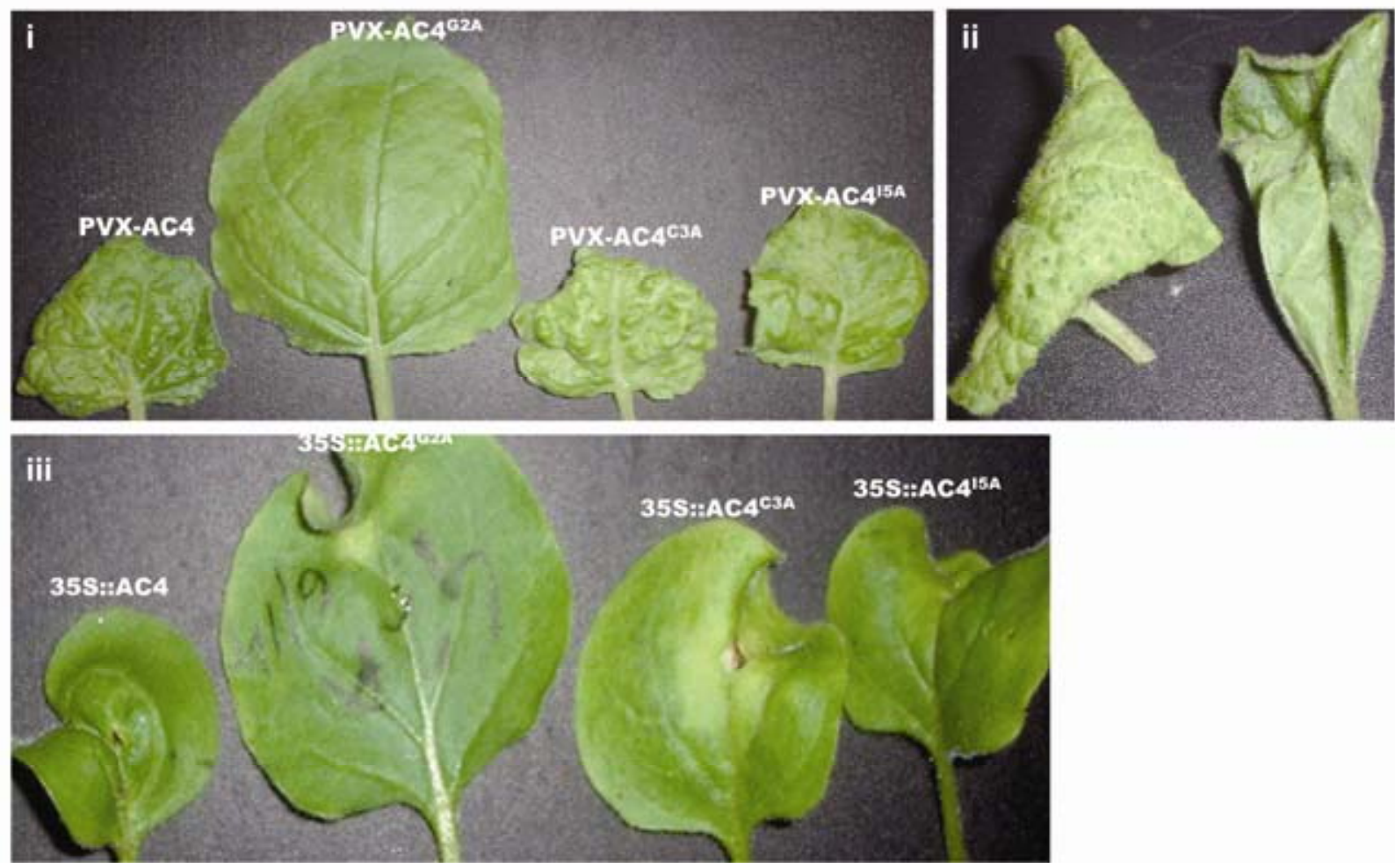
in Figure 3Bi and ii. Leaves of plants infected by PVX-AC4, PVX-AC4 ${ }^{\mathrm{C} 3 \mathrm{~A}}$, and PVX-AC4 $4^{\mathrm{ISA}}$ showed a considerable reduction and distortion of leaf size compared with $\mathrm{AC} 4^{\mathrm{G} 2 \mathrm{~A}}$, which caused no apparent symptoms (Fig. 3Bi). At advanced stages $\mathrm{AC} 4, \mathrm{AC} 4^{\mathrm{CA}}$, and $\mathrm{AC} 4^{\mathrm{ISA}}$ tended to cause different modifications on the leaves (Fig. 3Bii), which exhibited a feathery aspect. Since $\mathrm{AC} 4, \mathrm{AC} 4{ }^{\mathrm{C} 3 \mathrm{~A}}$, and $\mathrm{AC} 4^{\mathrm{ISA}}$ bind to membranes whereas $\mathrm{AC} 4^{\mathrm{G} 2 \mathrm{~A}}$ does not, these results suggest that $\mathrm{AC} 4$ pathogenecity is dependent on Gly-2 and, most likely, membrane binding. To confirm that differences in symptom production were not due to chimeric virus replication and movement, a Northern blot analysis was conducted on leaf samples collected from inoculated and systemically infected leaves, using an AC4 probe. Results showed equal levels of viral RNA in inoculated leaves for all constructs (Fig. 4A). Similar results were observed on systemically infected leaves (Fig. 4B). These results therefore provide further evidence that AC4 pathogenecity depends on Gly-2 and, most likely, membrane binding and that these mutations do not influence chimeric virus movement. Northern analysis results of control plants inoculated with PVX are shown in Figure 4C.

We also investigated symptoms caused by AC4 and mutants under the control of the $35 \mathrm{~S}$ promoter. Leaf patches were agroinoculated with $35 \mathrm{~S}:: \mathrm{AC} 4,35 \mathrm{~S}:: \mathrm{AC}^{\mathrm{G} 2 \mathrm{~A}} 35 \mathrm{~S}:: \mathrm{AC}^{\mathrm{C} 3 \mathrm{~A}}$, and 35S::AC4 ${ }^{\mathrm{ISA}}$ from pEarleygate100 (Earley et al. 2006). Examination of the leaves showed no apparent differences in patches inoculated with $\mathrm{AC} 4, \mathrm{AC} 4{ }^{\mathrm{C} 3 \mathrm{~A}}$, and $\mathrm{AC} 4^{\mathrm{ISA}}$, as all three chimeras caused reduced growth and distortion, whereas $A C 4^{\mathrm{G} 2 \mathrm{~A}}$ caused only a slight distortion on the inoculated leaf (Fig. 3Biii). To compare levels of mRNA, total RNA was extracted from the inoculated leaves and was analyzed by Northern blot. Similar to observations made in PVX chimeras, no differences were observed on the mRNA levels of any of the four $35 \mathrm{~S}$ chimeras (Fig. 4D). Therefore, differences in symptoms could not be due to differences in transcription. This is further evidence that Gly-2 and membrane binding are required for pathogenecity of AC4.

\section{EACMCV-encoded AC4 is a suppressor of VIGS.}

To determine whether AC4 suppresses RNA silencing, we used the GFP-transgenic $N$. benthamiana plants (line 16c) described by Voinnet and associates (1999). In this assay, line $16 \mathrm{c}$ plants fluoresce green under UV light, due to expression of the GFP transgene. Upon inoculation of these plants with a recombinant plasmid containing a GFP sequence, however, further expression of GFP is blocked and the plants display chlorophyll autofluorescence, as indicated by red fluorescence under long-wave UV light. In the presence of a suppressor of RNA silencing, however, the GFP silencing is blocked and the plants continue to exhibit green fluorescence. When these plants were infiltrated with PVX-GFP, transient or ectopic GFP expression was observed in the veins of new leaves from 6 days postinoculation (dpi) (Fig. 5Aa) under UV light. The intensity of the green fluorescence increased until $11 \mathrm{dpi}$ but was followed by a rapid replacement of the green fluorescence by chlorophyll red autofluorescence due to GFP silencing at 12 dpi (Fig. 5Ab) and by 18 dpi these plants were completely red fluorescent (Fig. 5Ac and d). Plants inoculated with PVXGFP/PVX-AC4 showed only a slight green fluorescence at 6 dpi (Fig. 5Ae). By 9 dpi, and especially at 12 dpi, however, these plants displayed an intense green fluorescence on newly emerging leaves (Fig. 5Af). At 18 dpi, when PVX-GFP plants were completely red fluorescent, PVX-GFP/PVX-AC4 plants only showed flecks of red fluorescence, indicating a low level of silencing (Fig. 5Ag), and most of the leaf continued to show silencing suppression at $30 \mathrm{dpi}$ (Fig. 5Ah). These results suggest that AC4 most likely suppresses VIGS by interfering with the spread of the RNA-silencing signal.

\section{AC4 suppression of VIGS requires Gly-2.}

The influence of the consensus $N$-myristoylation motif of AC4 on VIGS suppression was investigated using PVX chimeras. Line $16 \mathrm{c}$ plants were agroinfiltrated with PVX-GFP, PVXGFP/PVX-AC4, PVX-GFP/PVX-AC4 ${ }^{\mathrm{G} 2 \mathrm{~A}}$, PVX-GFP/PVX$\mathrm{AC} 4^{\mathrm{C} 3 \mathrm{~A}}$, and PVX-GFP/PVX-AC4 ${ }^{\mathrm{ISA}}$ and were placed in the growth chamber. Plants inoculated with PVX-GFP/PVX$\mathrm{AC} 4^{\mathrm{G} 2 \mathrm{~A}}$ displayed a similar pattern of GFP expression and silencing as was observed in plants inoculated with PVX-GFP alone (Fig. 5Ba and c). In contrast, similar to observations recorded with PVX-GFP/PVX-AC4 (Fig. 5Bb), plants inoculated with PVX-GFP/PVX-AC4 ${ }^{\mathrm{C} 3 \mathrm{~A}}$ and, especially, PVXGFP/PVX-AC4 ${ }^{15 A}$ showed a considerable reduction of GFP silencing, as indicated by continued green fluorescence at $18 \mathrm{dpi}$ (Fig. 5Bd and e) and beyond (data not shown). It is important to note that, $\mathrm{AC} 4{ }^{\mathrm{C} 3 \mathrm{~A}}$ was less efficient than $\mathrm{AC} 4$ and $\mathrm{AC} 4{ }^{\mathrm{ISA}}$ in suppressing GFP silencing, as indicated by a higher intensity of red fluorescence. Because $\mathrm{AC} 4^{\mathrm{C} 3 \mathrm{~A}}$ and, especially, $\mathrm{AC} 4^{\mathrm{ISA}}$ localize with membranes, it is likely that the ability of AC4 to efficiently suppress VIGS is dependent on membrane binding, which in turn, is dependent on Gly-2.

To quantify GFP mRNA levels, total RNA was extracted from young leaves and GFP mRNA levels were determined using Northern blot. Results of the analyses showed high levels of GFP mRNA in leaves of plants coinoculated with PVXGFP/PVX-AC4 compared with levels in plants inoculated with PVX-GFP alone or in mock-inoculated plants (Fig. 6A), confirming that AC4 suppresses VIGS. Similarly higher levels of GFP mRNA were observed in plants inoculated with PVXGFP/PVX-AC4 $4^{\mathrm{ISA}}$ and PVX-GFP/PVX-AC4 ${ }^{\mathrm{C} 3 \mathrm{~A}}$. A Northern analysis was also conducted with a PVX CP probe. Results showed only barely observable levels of PVX in plants inoculated with PVX-GFP and PVX-GFP/PVX-AC4 ${ }^{\mathrm{G} 2 \mathrm{~A}}$, presumably as a result of silencing of PVX-GFP and PVX-AC4 ${ }^{\mathrm{G} 2 \mathrm{~A}}$, respectively (Fig. 6B). In contrast, and consistent with the extent of silencing suppression, very high levels of PVX chimera were observed in plants inoculated with PVX-GFP/PVX-AC4 and PVX-GFP/PVX-AC4 ${ }^{\mathrm{ISA}}$ and, to a lesser extent, in plants inoculated with PVX-GFP/PVX-AC4 ${ }^{\mathrm{C} 3 \mathrm{~A}}$ (Fig. 5B). The fact that the PVX probe barely detected viral RNA in plants inoculated with PVX-GFP and PVX-GFP/PVX-AC4 ${ }^{\mathrm{G} 2 \mathrm{~A}}$ suggests that the spread of GFP silencing in young leaves was due more to the spread of the silencing signal than to a de novo silencing by PVX-GFP. Taken together, these results confirm that the

Fig. 3. Nicotiana benthamiana plant phenotypes after agroinfiltration with East African cassava mosaic Cameroon virus-encoded AC4 and mutants from the Potato virus $X$ (PVX) vector and under the control of $35 \mathrm{~S}$ promoter. A, (a) At 12 days postinoculation (dpi) PVX induced no apparent symptoms, whereas (b) PVX-AC4 included leaf mosaic, curling, folding, and stem and petioles epinasty. (c) PVX-AC4 ${ }^{\mathrm{G} 2 \mathrm{~A}}$ caused no apparent symptoms. (d) Symptoms caused by PVX-AC4 ${ }^{\mathrm{C} 3 \mathrm{~A}}$ and PVX-AC4 ${ }^{\mathrm{ISA}}$ were similar to (e) symptoms caused by PVX-AC4. B, (i) Leaves of PVX-AC4 ${ }^{\mathrm{G} 2 \mathrm{~A}}-\mathrm{inoculated}$ plants showed no apparent symptoms, whereas leaves of plants inoculated with PVX-AC4, PVX-AC4 ${ }^{\mathrm{C} 3 \mathrm{~A}}$, and PVX-AC4 ${ }^{\mathrm{I} A \mathrm{~A}}$ showed mosaic, leaf distortion, dark-green islands, deep veins, and size reduction. (ii) By $20 \mathrm{dpi}$, plants inoculated with PVX-AC4, PVX-AC4 ${ }^{\mathrm{C} 3 \mathrm{~A}}$, and PVX-AC4 ${ }^{\mathrm{I5A}}$ typically displayed twisted and feathery leaves. (iii) When expressed under the control of the $35 \mathrm{~S}$ promoter, no apparent differences were observed in patches inoculated with $\mathrm{AC} 4$, $\mathrm{AC} 4{ }^{\mathrm{C} 3 \mathrm{~A}}$, and $\mathrm{AC} 4{ }^{\mathrm{ISA}}$. In contrast, $\mathrm{AC} 4^{\mathrm{G} 2 \mathrm{~A}}$ caused only a slight distortion of the inoculated leaf with no apparent effect on growth. 
ability of AC4 to suppress silencing is dependent on membrane binding.

\section{AC4 suppresses PTGS inefficiently.}

The ability of AC4 and mutants to suppress posttranscriptional silencing was investigated using the $35 \mathrm{~S}$ promoter. Thus, AC4 and mutants were cloned into pEarleygate100 (Earley et al. 2006) to obtain $35 \mathrm{~S}:: \mathrm{AC} 4,35 \mathrm{~S}:: \mathrm{AC} 4^{\mathrm{G} 2 \mathrm{~A}}, 35 \mathrm{~S}:: \mathrm{AC} 4^{\mathrm{C} 3 \mathrm{~A}}$, and $35 \mathrm{~S}:: \mathrm{AC} 4^{\mathrm{ISA}}$. The silencing inducer, full-length GFP, was also expressed under the control of the $35 \mathrm{~S}$ promoter. These constructs and the Tombusvirus p19 protein, an efficient suppressor of PTGS, were each coinfiltrated to line 16c plants. Observation of these plants under long-wave UV light showed a bright green fluorescence on patches singly infiltrated with GFP within 2 days. By 4 dpi however, the bright green fluorescence had been replaced by red fluorescence due to GFP silencing (Fig. 5Ca). In contrast, patches coinfiltrated with GFP and AC4 as well as with GFP and AC4 and mutants continued to exhibit bright green fluorescence at $4 \mathrm{dpi}$ (Fig. 5Cb through e), which persisted for up to 7 dpi in patches infiltrated with $\mathrm{AC} 4^{\mathrm{G} 2 \mathrm{~A}}$ before being replaced by red fluorescence. However, patches coinfiltrated with p19 exhibited very bright green fluorescence at 4 dpi (Fig. 5Cf) and continued to display bright green fluorescence at $12 \mathrm{dpi}$, when the green fluorescence was replaced by red fluorescence. These results show that EACMCV-encoded AC4 is an inefficient suppressor of local gene silencing, rather, it suppresses the systemic phase of silencing efficiently.

\section{AC4 suppresses RNA silencing a step downstream of siRNA production.}

Since AC4 efficiently suppressed systemic silencing, we investigated whether it affects the production or spread, or both, of siRNAs, which act as guides to the RNA-induced silencing complex (RISC) (Hamilton and Baulcombe 1999; Zamore et al. 2000). Thus, we extracted low molecular-weight RNA from inoculated leaves and from newly emerged leaves of plants inoculated with PVX-GFP/PVX-AC4 and from leaves of plants singly inoculated with PVX-GFP. Probes were prepared from a full-length GFP sequence cloned into pSPT18 transcription vector Roche Diagnostics, Indianapolis, IN, U.S.A.). Sense and antisense runoff transcripts were labeled with [ $\alpha$ ${ }^{32} \mathrm{P}$ ]CTP, using the SP6/T7 RNA transcription kit (Roche Diagnostics) as described by the manufacturer. The blot results showed a high level of GFP sense and antisense siRNA in leaves inoculated with PVX-GFP/PVX-AC4 as well as in leaves inoculated with PVX-GFP alone and leaves inoculated with PVX-GFP/PVX-AC4 ${ }^{\mathrm{G} 2 \mathrm{~A}}$ (Fig. 6C). In contrast, very low levels of siRNA were observed in young green-fluorescent leaves of plants inoculated with PVX-GFP/PVX-AC4. Since inoculated leaves contained high levels of siRNA whereas newly emerged leaves displayed very low levels, AC4 appears not to interfere with the production of siRNA. Instead, it inhibits its systemic spread. The similarity between the levels of siRNA in plants inoculated with PVX-GFP/PVX-AC4 ${ }^{\mathrm{G} 2 \mathrm{~A}}$ and PVX-GFP is consistent with GFP silencing in these plants.

\section{DISCUSSION}

Determination of the cellular address of a protein is an important step in understanding how the protein interacts with host factors to carry out its functions. This is especially important in the study of plant virus proteins, since these viruses encode very few proteins and have to depend heavily on interactions with the host factors to counter the host defense mechanism and ensure virus replication and transcription for their survival. In this study, we have used confocal imaging to show that the AC4 protein from EACMCV binds preferentially with the PM but also with cytosolic membranes. Membrane binding is a characteristic of acylated proteins; thus, we submitted the

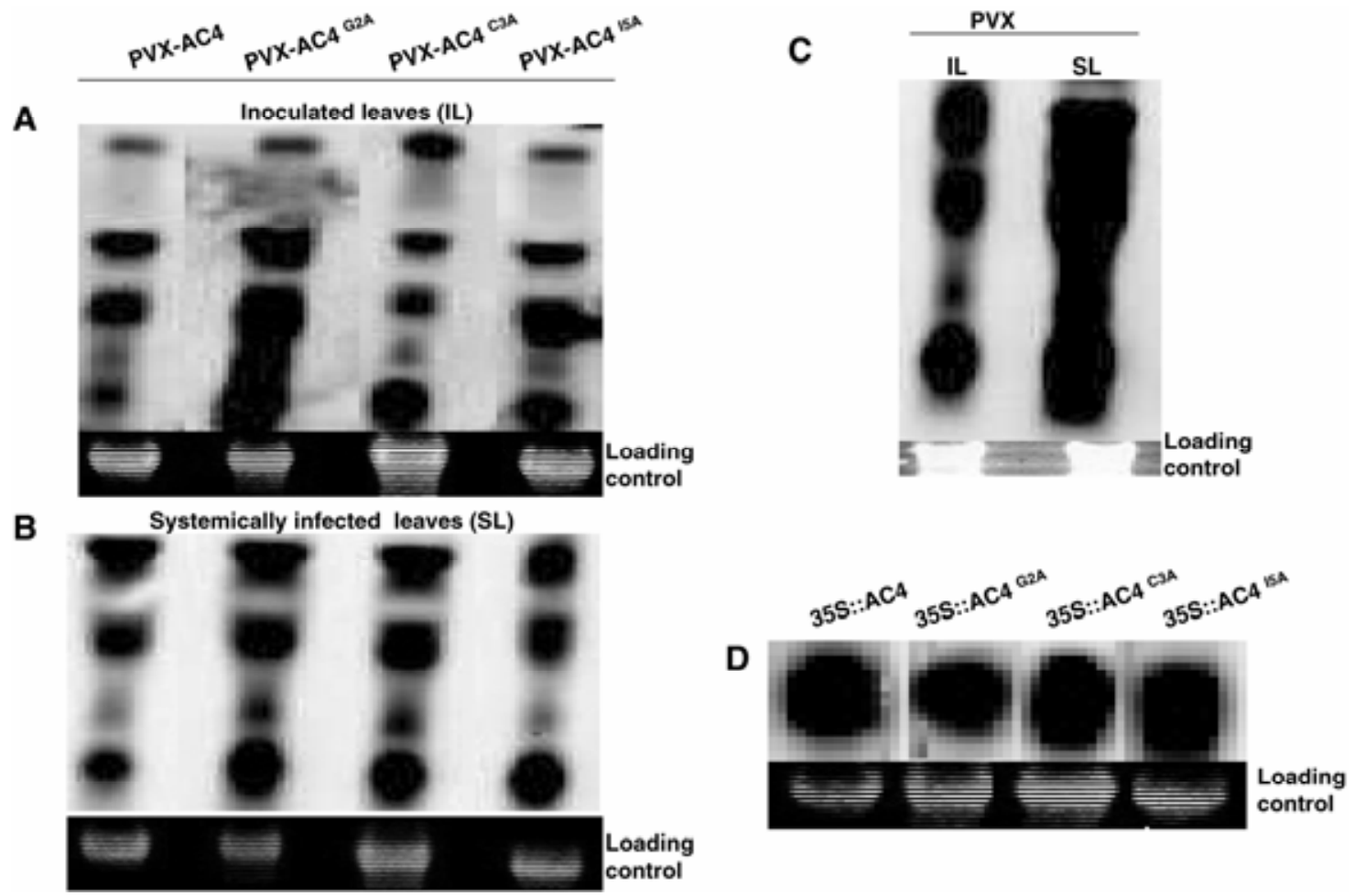

Fig. 4. Northern blot hybridization of RNA extracted from leaf tissues of Nicotiana benthamiana plants inoculated with Potato virus $X$ (PVX) and 35S promoter chimeras containing AC4 and mutants. A and B, Similar levels of PVX-AC4, PVX-AC4 ${ }^{\mathrm{G} 2 \mathrm{~A}}, \mathrm{PVX}-\mathrm{AC} 4{ }^{\mathrm{C} 3 \mathrm{~A}}$, and PVX-AC4 $4^{\mathrm{ISA}}$ were observed in inoculated and systemically infected leaves. C, Control plants inoculated with PVX alone showed a systemic spread of viral RNA. D, Similarly, there were no differences between mRNA of AC4 and its mutants expressed under the control of the $35 \mathrm{~S}$ promoter. 
AC4 protein sequence to myristoylation predictors (Bologna et al. 2006; Eisenhaber et al. 2003; Falquet et al. 2002; MaurerStroh et al. 2002, 2004; Podell and Gribskov 2004) and identified an $N$-myristoylation motif, suggesting that AC4 is likely acylated. Using point mutations, we showed that the consensus $\mathrm{N}$-myristoylation motif is critical for membrane targeting and pathogenicity. It is therefore likely that $\mathrm{AC} 4$ requires the attachment of myristate at Gly-2 and palmitate at Cys-3 to bind to the plasma and cytosolic membranes from which it interacts with host factors to induce virus-like symptoms. Although palmitoylation provides additional energy to enable the myristoylated protein to stably target and anchor to membranes, it is not indispensable (Resh 1999). Thus, when we replaced Cys-3 with Ala, thereby eliminating the possibility of palmitate attachment, AC4 ${ }^{\mathrm{C} 3 \mathrm{~A}}-\mathrm{GFP}$ localized predominantly with cytosolic membranes; it was also highly concentrated on the perinuclear vesicles but mainly excluded from the nucleus. It is therefore likely that a myristoylated $\mathrm{AC} 4^{\mathrm{C} 3 \mathrm{~A}}-\mathrm{GFP}$ could bind to cytosolic membranes, but the energy provided by the myristate is not sufficient for efficient PM binding. A similar case cannot be

A
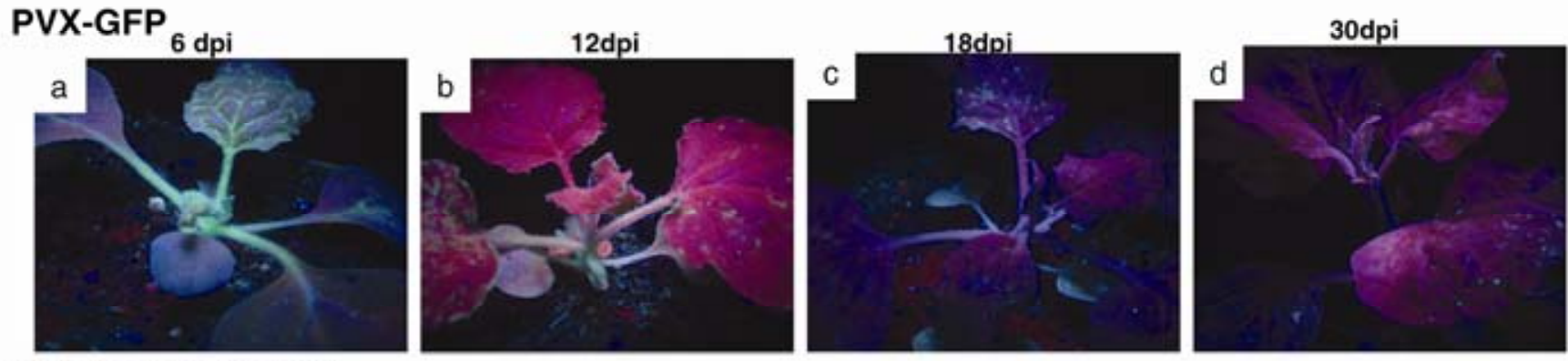

\section{PVX-GFP+PVX-AC4}
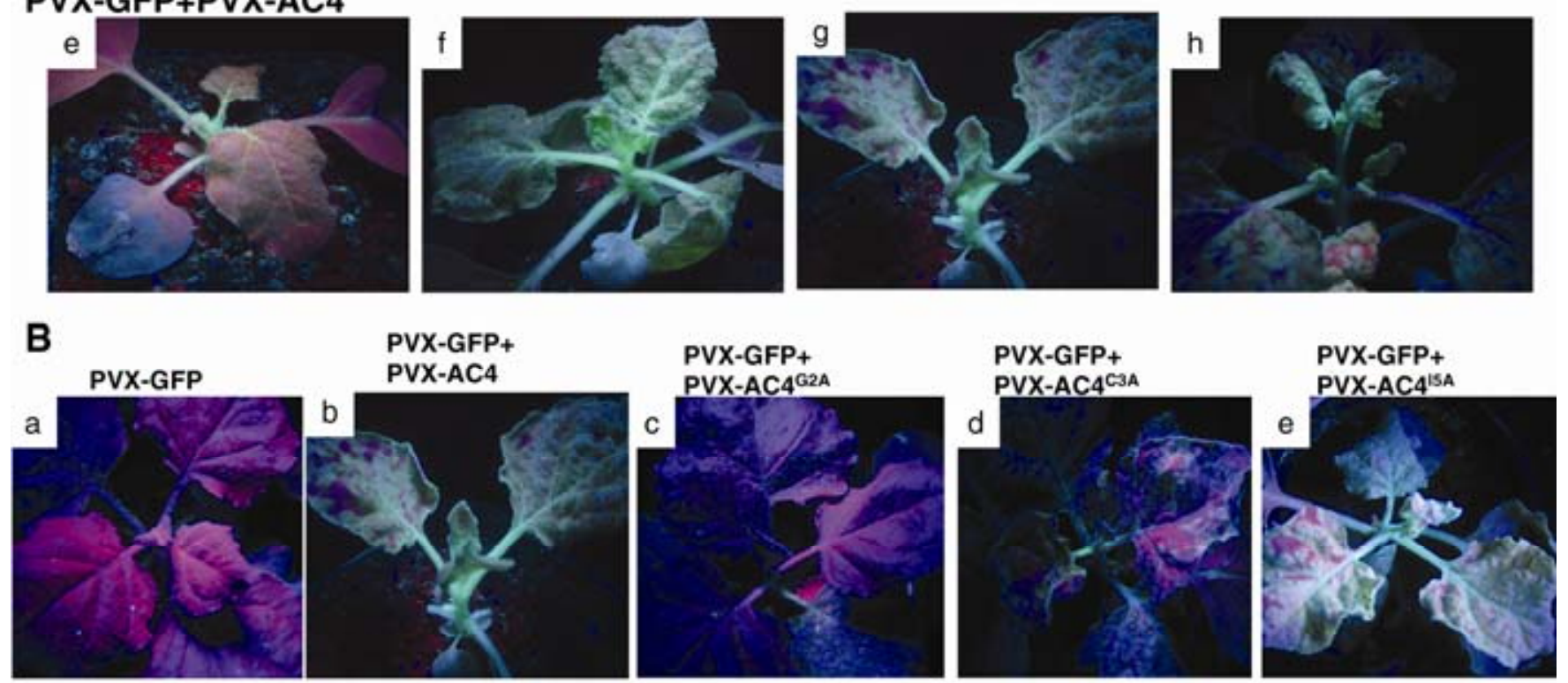

C
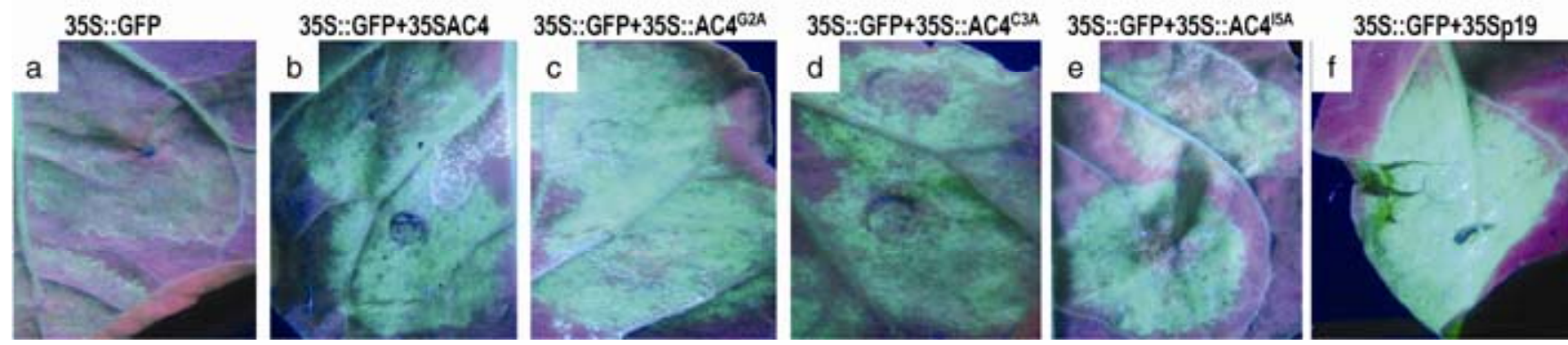

Fig. 5. Suppression of virus induced silencing of green fluorescent protein (GFP). A, (a) Systemic spread of green fluorescence in GFP transgenic Nicotiana benthamiana plants agroinfiltrated with Potato virus X (PVX)-GFP was observed 6 days postinoculation (dpi), and (b) by 12 dpi, it had almost been completely silenced. (c) By 18 dpi and (d) beyond there was complete silencing of green fluorescence as indicated by chlorophyll autofluorescence. Plants inoculated with PVX-GFP/PVX-AC4 showed a lower intensity of green fluorescence than (e) PVX-GFP plants at 6 dpi. By 9 dpi, and (f) especially at 12 dpi, there was bright green fluorescence in emerging leaves. (f) Newly emerging leaves continued to display green fluorescence at 18 dpi and beyond. B, (a) Line 16c plants inoculated with PVX-GFP/PVX-AC4 ${ }^{\mathrm{G} 2 \mathrm{~A}}$ showed a similar expression and silencing as observed in (c) plants inoculated with PVX-GFP. (b) In contrast, plants inoculated with PVX-GFP/PVX-AC4, (d) PVX-GFP/PVX-AC4 ${ }^{\mathrm{C} 3 \mathrm{~A}}$, and (e) PVX-GFP/PVX-AC4 ${ }^{\mathrm{ISA}}$ continued to express GFP, indicating suppression of silencing. C, Posttranscriptional gene silencing of GFP was assessed by singly infiltrating (a) 35S::GFP, or by coinfiltrating (b) 35S::GFP/35S:: AC4, (c) 35S::GFP/35S:: AC4 ${ }^{\mathrm{G} 2 \mathrm{~A}}$, (d) $35 \mathrm{~S}:: \mathrm{GFP} / 35 \mathrm{~S}:: \mathrm{AC}^{\mathrm{C} 3 \mathrm{~A}}$, (e) $35 \mathrm{~S}:: \mathrm{GFP} / 35 \mathrm{~S}:: \mathrm{AC} 4^{15 \mathrm{~A}}$, and (f) $35 \mathrm{~S}:: \mathrm{GFP} / 35 \mathrm{~S}:: \mathrm{p} 19$. 
made for $\mathrm{AC} 4^{\mathrm{G} 2 \mathrm{~A}}-\mathrm{GFP}$ localization, because myristoylation is a prerequisite for the palmitoylation of adjacent cysteine residues. Thus disruption of myristoylation (due to G2A mutation) presumably abolished palmitoylation of cysteine (Alland et al. 1994; Resh 1994), thereby inhibiting membrane binding. The G2A mutation instead created a consensus chloroplast-targeting motif, thus explaining $\mathrm{AC} 4{ }^{\mathrm{G} 2 \mathrm{~A}}-\mathrm{GFP}$ labeling of the chloroplast. $N$-myristoylation predictors (Falquet et al. 2002; MaurerStroh et al. 2002, 2004; Podell and Gribskov 2004) indicate that the fifth amino acid is not essential for myristoylation and membrane binding. In agreement with these models, $\mathrm{AC}^{\mathrm{ISA}}$ GFP, like AC4-GFP, appeared to bind with the PM and cytosolic membranes. Moreover, as predicted, fusion of $\mathrm{AC} 4$ to the $\mathrm{C}$ terminus of GFP (GFP-AC4) disrupted membrane localization and this can be explained by the $\mathrm{C}$-terminal position of the motif in GFP-AC4, since myristoylation may only occur when the motif is at the $\mathrm{N}$ terminus. These data are supported by $\mathrm{N}$ myristoylation prediction algorithms, especially the Plant-Specific Myristoylation Predictor, which is designed specifically for plants and claims $100 \%$ accuracy in identifying plant myristoylated proteins (Podell and Gribskov 2004). Subsequent studies will determine possible myristoylation of AC4 as well as identify host factors that interact with it. Such data will provide us with valuable information on VIGS suppression by AC4 and its overall ability to weaken host defense.

A critical examination of the membranes targeted by AC4GFP shows that GFP expression is not uniformly distributed but is concentrated in microdomains, which were clearly enriched with high levels of AC4-GFP. This is consistent with the view that membranes have specific microcompartments con- taining various lipids and proteins (Maurer-Stroh et al. 2004; Simons and Ikonen 1997). Similar domains have been identified in animal cells and are characterized by detergent-resistant lipid fractions and cell-type specific populations of proteins (Edidin 2003; Nebl et al. 2002; von Haller et al. 2001) and have been proposed to form platforms for numerous cellular events including membrane trafficking, signaling, and cell adhesion. They have also been shown to contain many known myristoylated proteins involved in signaling pathways such as Src family tyrosine kinases (Kovarova et al. 2001), MARCKS (Arbuzova et al. 2002), CAP23 (Arbuzova et al. 2002), and the HIV Nef protein (Wang et al. 2000). These myristoylated proteins have been shown to localize with the cytoplasmic surface of the PM and the inner layer leaflet of the PM bilayer, from which they facilitate interaction with other proteins (Resh 1999). Since plant proteins with a consensus $N$-myristoylation motif may or may not be involved in disease signaling (Loh et al. 1998; de Vries et al. 2006), it is not clear whether AC4 is involved in disease signaling. However, as demonstrated in this study, it produces virus-like symptoms and suppresses VIGS, which is part of the plant's innate immunity system.

Contrary to our results, Vanitharani and associates (2004) reported that EACMCV AC4 appeared not to suppress PTGS. This discrepancy may be explained, at least partially, by the fact that AC4 is efficient only at suppressing the systemic phase of RNA silencing, as demonstrated in our study. It would, therefore, have been difficult to observe silencing suppression in the Vanitharani and associates (2004) study, since they used pCambia2300, a weak transient expression vector. Indeed, our data shows that AC4 does not block the production
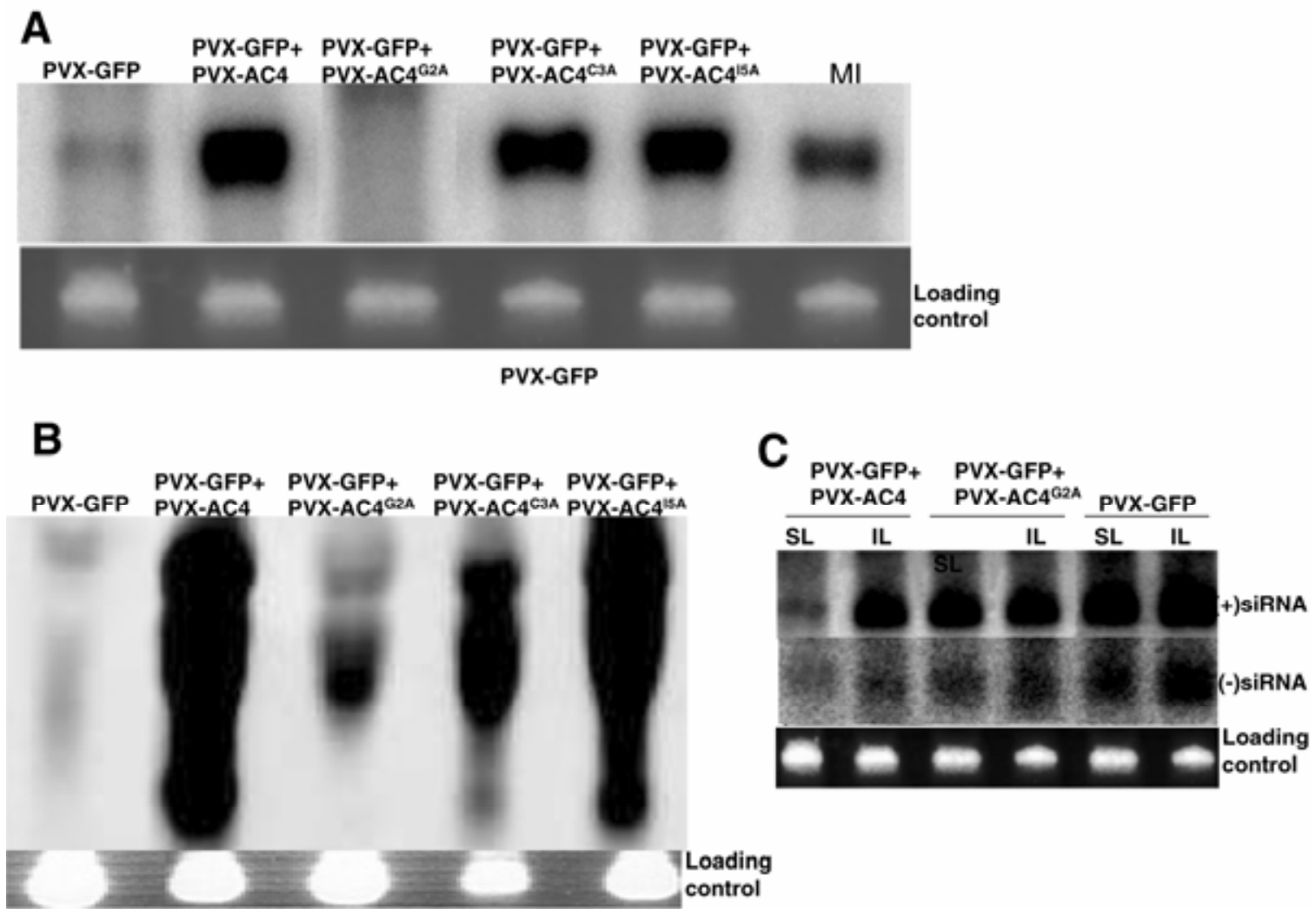

Fig. 6. Northern blot detection of green fluorescent protein (GFP) mRNA levels indicating suppression of virus-induced gene silencing. A, Total RNA was extracted from Nicotiana benthamiana leaf tissues 18 days after infiltration with Potato virus X (PVX)-GFP), PVX-GFP/PVX-AC4, PVX-GFP/PVX$\mathrm{AC}^{\mathrm{G} 2 \mathrm{~A}}$, PVX-GFP/PVX-AC4 ${ }^{\mathrm{C} 3 \mathrm{~A}}$, PVX-GFP/PVX-AC4 ${ }^{\mathrm{I5A}}$, as well as from mock-inoculated (MI) plants. Probes were prepared from full-length GFP sequence. B, When probed with PVX coat protein, almost total degradation of PVX was observed in plants inoculated with PVX-GFP and PVX-GFP/PVX$\mathrm{AC} 4{ }^{\mathrm{G} 2 \mathrm{~A}}$. C, Inhibition of siRNA systemic spread by AC4. GFP siRNA from inoculated leaves (IL) and upper systemically infected leaves (SL) of plants inoculated with PVX-GFP and PVX-GFP/PVX-AC4 and PVX-GFP/PVX-AC4 ${ }^{\mathrm{G} 2 \mathrm{~A}}$ was hybridized with sense and antisense GFP transcripts labeled with $[\alpha-$ $\left.{ }^{32} \mathrm{P}\right] \mathrm{CTP}$ using SP6/T7 RNA transcription. 
of siRNA, the guide of RISC, but does interfere with its spread. The role of membrane localization in the suppression of VIGS is supported by the fact that disruption of membrane localization abolishes the ability of AC4 to suppress VIGS. This may explain why suppression of VIGS is dependent on the consensus $\mathrm{N}$-myristoylation signal. EACMCV AC4 protein is the first suppressor of RNA silencing to target the PM and, thus, provides an opportunity for the determination of the role of the PM on the phenomenon of RNA silencing. Furthermore, because AC4 pathogenicity is dependent on the consensus $\mathrm{N}$ myristoylation motif, this protein can provide useful information on the ability of virus to counter the defense of the plant and cause a disease. Moreover, an examination of homologous proteins (C4 or AC4) in other geminiviruses, some of which are listed in Table 1, shows that they have the consensus $N$ myristoylation motif. All these viruses with the $N$-myristoylation motif are phylogenetically thought to have evolved recently, and this may be an adaptation to host conditions, since the AC4 protein determines host range (Bradeen et al. 1997). It is, therefore, highly likely that these viruses evolved the AC4 protein to be more aggressive, a situation that would be consistent with the view that these viruses are extremely plastic and have the ability to evolve very rapidly in response to changing cropping systems (Seal et al. 2006).

Due to its hydrophobic nature, the cell PM acts as a selective barrier that physiologically precludes the passage of hydrophilic proteins. Thus, although there is a dearth of information on the role of internal receptors in plant virus infection, it is highly likely that such receptors play a role in plant virus infection. The EACMCV AC4 protein, therefore, provides the opportunity to explore such receptors and their possible involvement in virus infection. Confirmation of a role for internal receptors in plant virus infection would be consistent with animal viruses, whose proteins, especially myristoylated ones, have been shown to bind to receptors on the internal surface of the PMs to facilitate infection (Matsubara et al. 2005; Robbins et al. 1995). Finally, since antibodies expressed from the nuclear genome and targeted to the chloroplast are highly stable (Jobling et al. 2003; Twyman et al. 2003), the chloroplasttargeting motif of $\mathrm{AC} 4{ }^{\mathrm{G} 2 \mathrm{~A}}$ can be fused to candidate recombinant antibodies for chloroplast targeting; therefore, there are potential medical benefits to be obtained from the chloroplastlocalized $\mathrm{AC} 4^{\mathrm{G} 2 \mathrm{~A}}$.

\section{MATERIALS AND METHODS}

\section{Cloning and expression of $\mathrm{AC4}$ and mutants.}

The AC4 protein of EACMCV clone pVF1.6EA (Fondong et al. 2000) was used in this study. To determine subcellular localization of AC4 protein, the AC4 ORF was polymerase chain reaction (PCR) amplified, using primers forward, GGC TCGAATTCATGGGGTGCCTCATCTCCATG and reverse, CAGACACTGCAGCTAAATGCTGGCCCTCCCCCCT (the underlined sequences are EcoRI and PstI sites, respectively). The PCR product was isolated, digested with EcoRI and PstI, and was cloned into pBluescript ( $\mathrm{SK}-$ ) to obtain clone pSKAC4. To conduct subcellular localization, AC4 was fused to both the $\mathrm{N}$ and $\mathrm{C}$ termini of the enhanced GFP. AC4 was fused to the $\mathrm{N}$ terminus of GFP by isolating AC4 from pSK-AC4 with HindIII and BamHI and cloning into the same sites in plasmid pHBT95::sGFP(S65T) (Chiu et al. 1996). The GFPAC4 fusion was PCR amplified with Gateway-compatible (Invitrogen, Carlsbad, CA, U.S.A.) primers; attB1+ATGGTGAG CAAGGGCGAG and reverse attB2+CCTAAATGCTGGCCC TCCCCCCT. PCR products were purified and recombined with pDONR 207 (Invitrogen) to obtain the Entry vector (Invitrogen), as described by the manufacturer. The recombination mixture was transformed into Escherichia coli (strain DH5 $\alpha$ ). Miniprep aliquots from recombinant colonies were recombined with pEarleyGate100 (Earley et al. 2006). To investigate the pathogenicity of AC4, the Entry vector containing AC4 was recombined with the Gateway (Invitrogen) version of the PVX vector (provided by G. Martin, Cornell University, Ithaca, NY, U.S.A.) (Fig. 1B) and with pEarleygate100 (Earley et al. 2006) (Fig. 1C). These plasmids were transformed into E. coli (strain $\mathrm{DH} 5 \alpha$ ). Minipreps of recombinant colonies were transformed into A. tumefaciens GV3101 for transient expression in N. benthamiana.

Three point mutations were introduced to the consensus $\mathrm{N}$ myristoylation motif of AC4 by replacing Gly-2, Cys-3, Ile-5 with alanine to obtain AC4 mutants G2A, C3A, and I5A, respectively, and were confirmed by sequencing. GFP N- and C-terminal fusions of these mutants were obtained as described for GFP-AC4. In the RNA silencing suppression assay, AC4 and mutants were cloned into pEarleyGate100 and PVX (Fig. 1).

\section{Plant infiltration.}

Binary constructs carrying individual genes were introduced into A. tumefaciens (strain GV3101) using the freeze-thaw method, and cultures were grown at $28^{\circ} \mathrm{C}$. Agrobacterium suspensions were pelleted and resuspended in a solution contain-

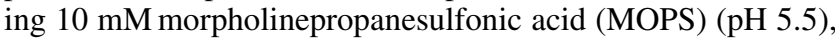
$10 \mathrm{mM} \mathrm{MgCl}_{2}$, and $100 \mu \mathrm{M}$ acetosyringone to an optical density at $600 \mathrm{~nm}$ of 1.0. Four- to six-leaf $N$. benthamiana seedlings were infiltrated on the abaxial surface of the first two true leaves. A 1-ml, needleless syringe was used in these infiltrations. The infiltrated plants were placed in a growth chamber with 16-h photoperiod and a day temperature of $22^{\circ} \mathrm{C}$ and night temperature of $18^{\circ} \mathrm{C}$.

\section{RNA analysis.}

To analyze samples inoculated with PVX chimeras, leaf samples were collected from systemically infected leaves of $N$. benthamiana plants (12 dpi); for $35 \mathrm{~S}$ promoter expression, samples were extracted from inoculated patches 3 dpi. Total RNA was extracted using Tri-Reagent (Molecular Research Center, Cincinnati, OH, U.S.A.). DNA traces were removed with DNA-free kit (Ambion, Austin, TX, U.S.A.) as described by the manufacturer. The quality of RNA was checked by electrophoresis. Total RNA $(15 \mu \mathrm{g})$ was heated at $55^{\circ} \mathrm{C}$ for $5 \mathrm{~min}$ prior to separation in a $1.2 \%$ agarose/MOPS/formaldehyde gel in $1 \times$ MOPS buffer. The RNA was transferred overnight to a Nylon blotting membrane (Schleicher and Schuell, Keene, NH, U.S.A.) and was hybridized with gene-specific probes using the North2South Chemiluminescent hybridization and detection kit from Pierce Biotechnology, Inc. (Rockford, IL, U.S.A.) or for $2 \mathrm{~h}$ at $62^{\circ} \mathrm{C}$ in QuikHyb hybridization solution buffer (La Jolla, CA, U.S.A.) with a $\left[\alpha-^{32} \mathrm{P}\right]$ ATP labeled with full-length GFP sequence for GFP sequence for GFP mRNA and siRNA detection. Membranes were developed with a phosphoimager and were analyzed with the Bio-Rad (Hercules, CA, U.S.A.) Quantity one imaging package.

\section{Microscopy.}

Leaf pieces were excised, gently vacuum infiltrated with water and placed in single-welled LabTek Nalgene Nunc chambered coverglass system (Nunc \#155361; Nalgene Nunc International, Naperville, IL, U.S.A.) for confocal imaging. Images were acquired on an inverted Zeiss LSM 510 VIS laser-scanning microscope (Carl Zeiss, Inc., Oberkochen, Germany) using a Zeiss63X C-Apochromat (NA 1.2) objective lens. Multichannel images of sGFP and chloroplast autofluorescence were acquired using the $488 \mathrm{~nm}$ line of an ArgonKrypton laser with the 500 to 550 band pass and 650 long-pass 
emission filters, respectively. Images were captured as single optical sections or as a z-series of optical sections, and z-series data sets were displayed as single maximum intensity projection generated using Zeiss LSM software v3.2. Images were processed and assembled for publication in Adobe Photoshop 6.0 .

\section{ACKNOWLEDGMENTS}

This project was supported by National Science Foundation grant number 0344786 . We thank D. Baulcombe for providing GFP transgenic $N$. benthamiana. R. V. Chowda Reddy was supported by National Institute of Health grant number P20 RR16472-04 from the IDeA Networks of Biomedical Research Excellence (INBRE) program of the Center for Research Resources.

\section{LITERATURE CITED}

Alland, L, Peseckis, S. M., Atherton, R. E., Berthiaume, L., and Resh, M. D. 1994. Dual myristylation and palmitylation of Src family member p59fyn affects subcellular localization. J. Biol. Chem. 269:1670116705.

Arbuzova, A., Schmitz, A. A., and Vergeres, G. 2002. Cross-talk unfolded: MARCKS proteins. Biochem J. 362:1-12.

Bologna, G., Yvon, C., Duvaud, S., and Veuthey, A. L. 2004. N-Terminal myristoylation predictions by ensembles of neural networks. Proteomics 4:1626-1632.

Bradeen, J. M., Timmermans, M. C., and Messing, J. 1997. Dynamic genome organization and gene evolution by positive selection in geminivirus (Geminiviridae). Mol. Biol. Evol. 14:1114-24.

Buttner, D., and U. Bonas. 2002. Getting across-bacterial type effector proteins on their way to the plant cell. EMBO (Eur. Mol. Biol. Organ.) J. 21:5313-5322

Chapman, S., Kavanagh, T. and D. Baulcombe. 1992. Potato virus X as a vector for gene expression in plants. Plant J. 2:549-557.

Chiu, W., Niwa, Y., Zeng, W., Hirano, T. Kobayashi, H. and Sheen. J. 1996. Engineered GFP as a vital reporter in plants. Curr. Biol. 6:325330

de Vries, J. S., Andriotis, V. M. Wu, A. J. and Rathjen, J. P. 2006. Tomato Pto encodes a functional $N$-myristoylation motif that is required for signal transduction in Nicotiana benthamiana. Plant J. 45:31-45.

Dolja, V. V. 2003. Beet yellows virus: The importance of being different. Mol. Plant Pathol. 4:91-98.

Earley, K. W, Haag, J. R., Pontes, O., Opper, K., Juehne, T., Song, K., and Pikaard, C. S. 2006. Gateway-compatible vectors for plant functional genomics and proteomics. Plant J. 45:616-629.

Edidin, M. 2003. The state of lipid rafts: From model membranes to cells Annu. Rev. Biophys. Biomol. Struct. 32:257-283.

Eisenhaber, F., Eisenhaber, B., Kubina, W., Maurer-Stroh, S., Neuberger, G., Schneider, G., and Wildpaner M. 2003. Prediction of lipid posttranslational modifications and localization signals from protein sequences: Big-Pi, NMT and PTS1. Nucleic Acids Res. 31:3631-3634.

Ellard-Ivey, M., Hopkins, R. B., White, T. J., and Lomax, T. L. 1999. Cloning, expression and $N$-terminal myristoylation of CpCPK1, a calcium-dependent protein kinase from zucchini (Cucurbita pepo L.). Plant Mol. Biol. 39:199-208.

Elmer, J. S., Brand, L., Sunter, G., Gardiner, W. E., Bisaro, D.M., and Rogers, S. G. 1988. Genetic analysis of the tomato golden mosaic virus. II. The product of the AL1 coding sequence is required for replication. Nucleic Acids Res. 16:7043-7060.

Etessami, P., Saunders K., Watts, J., and Stanley, J. 1991. Mutational analysis of complementary-sense genes of African cassava mosaic virus DNA A. J Gen Virol. 72:1005-12.

Falquet, L., Pagni, M., Bucher, P., Hulo, N., Sigrist, C. J., Hofmann, K., and Bairoch, A. 2002. The PROSITE database, its status in. Nucleic Acids Res. 30:235-238.

Fauquet, C. M., Bisaro, D. M., Briddon, R. W., Brown, J. K., Harrison, B. D., Rybicki, E. P. D., Stenger, C., and Stanley, J. 2003. Revision of taxonomic criteria for species demarcation in the family Geminiviridae, and an updated list of begomovirus species. Arch. Virol. 148:405-421.

Fondong, V. N., Pita, J. S., Rey, M. E. C., de Kockko, A., Beachy, R. N., and Fauquet C. M. 2000. Evidence of synergism between African cassava mosaic virus and a new double-recombinant geminivirus infecting cassava in Cameroon. J. Gen. Virol. 81:287-297.

Gutierrez, C. 2000. Geminiviruses and the plant cell cycle. Plant Mol Biol. 43:763-772.

Gutierrez, C., Ramirez-Parra, E., Mar Castellano, M., Sanz-Burgos, A. P.,
Luque, A. and Missich, R. 2004. Geminivirus DNA replication and cell cycle interactions. Vet. Microbiol. 98:111-119.

Hamilton, A. J., and Baulcombe, D. C. 1999. A species of small antisense RNA in posttranscriptional gene silencing in plants. Science 286:950-952.

Hoogstraten, R. A., Hanson, S. F., and Maxwell D. P. 1996. Mutational analysis of the putative nicking motif in the replication-associated protein $(\mathrm{AC} 1)$ of bean golden mosaic geminivirus. Mol. Plant-Microbe Interact. 9:594-599.

Ishitani, M., J. Liu D. P., Halfter, U., Kim C. S., Shi, W., and Zhu, J. K. 2000. SOS3 function in plant salt tolerance requires $N$-myristoylation and calcium binding. Plant Cell. 12:1667-1678.

Jobling, S. A., Jarman, C., The, M. M., Holmberg, N., Blake, C. and Verhoeyen, M. E. 2003. Immunomodulation of enzyme function in plants by single domain antibody fragments. Nat. Biotechnol. 21:77-80

Jupin, I., De Kouchkovsky, F., Jouanneau, F., and Gronenborn, B. 1994. Movement of tomato yellow leaf curl geminivirus (TYLCV): Involvement of the protein encoded by ORF C4._Virology. 204:82-90.

Kim, S. H., Ryabov, E. V., Brown, J. W. S., and Taliansky, M. 2004. Involvement of the nucleolus in plant virus systemic infection. Biochem. Soc. Trans. 32:557-560.

Kovarova, M., Tolar, P., Arudchandran, R., Draberova, L., Rivera, J., and Draber, P. 2001. Structure-function analysis of Lyn kinase association with lipid rafts and initiation of early signaling events after Fcepsilon receptor I aggregation. Mol. Cell Biol. 21:8318-8328.

Loh, Y. T., Zhou, J., and Martin, G. B. 1998. The myristylation motif of Pto is not required for disease resistance. Mol. Plant-Microbe Interact. 11:572-576.

Lu, S. X., and Hrabak, E. M. 2002. An Arabidopsis calcium-dependent protein kinase is associated with the endoplasmic reticulum. Plant Physiol. 128:1008-1021

Mallory, A. C., Ely, L., Smith, T. H., Marathe, R., Anandalakshmi, R., Fagard, M., Vaucheret, H., Pruss, G., Bowman, L., and Vance, V. B. 2001. HC-Pro suppression of transgene silencing eliminates the small RNAs but not transgene methylation or the mobile signal. Plant Cell 13:571-583.

Martin, M. L., and Busconi, L. 2000. Membrane localization of a rice calcium-dependent protein kinase $(\mathrm{CDPK})$ is mediated by myristoylation and palmitoylation. Plant J. 24:429-435.

Matsubara, M., Jing, T., Kawamura, K., Shimojo, N., Titani, K., Hashimoto, K., and Hayashi, N. 2005. Myristoyl moiety of HIV Nef is involved in regulation of the interaction with calmodulin in vivo. Protein Sci. 14:494-503.

Maurer-Stroh, S., Eisenhaber, B., and Eisenhaber, F. 2002. $N$-terminal Nmyristoylation of proteins: Refinement of the sequence motif and its $\operatorname{taxo} N$-specific differences. J. Mol. Biol. 317:523-540.

Maurer-Stroh, S., Gouda, M., Novatchkova, M., Schleiffer, A., Schneider, G., Sirota, F. L., Wildpaner, M., Hayashi, N., and Eisenhaber, F. 2004 MYRbase: Analysis of genome-wide glycine myristoylation enlarges the functional spectrum of eukaryotic myristoylated proteins. Genome Biol. 5:R21.

Maurer-Stroh, S., Eisenhaber, B., and Eisenhaber, F. 2002. N-terminal Nmyristoylation of proteins: Refinement of the sequence motif and its taxon-specific differences. J. Mol. Biol. 317:523-540.

Nebl, T., Pestonjamasp, K. N., Leszyk, J. D., Crowley, J. L., Oh, S. W., and Luna, E. J. 2002. Proteomic analysis of a detergent-resistant membrane skeleton from neutrophil plasma membranes. J. Biol. Chem. 277:43399-43409.

Pilartz, M., and Jeske, H. 1992. Abutilon mosaic geminivirus doublestranded DNA is packed into minichromosomes. Virology. 189:800-802

Podell, S., and Gribskov, M. 2004. Predicting N-terminal myristoylation sites in plant proteins. BMC Genomics $6,15 \mathrm{p}$.

Pooma, W., and Petty, I. T. 1996. Tomato golden mosaic virus open reading frame AL4 is genetically distinct from its C4 analogue in monopartite geminiviruses. J. Gen. Virol. 77:1947-1951.

Raices, M., Chico, J. M., Tellez-Inon, M. T., Ulloa, R. M. 2001. Molecular characterization of StCDPK1, a calcium-dependent protein kinase from Solanum tuberosum that is induced at the onset of tuber development. Plant Mol. Biol. 46:591-601.

Resh, M. D. 1994. Myristylation and palmitylation of Src family members: The fats of the matter. Cell. 76:411-413.

Resh, M. D. 1999. Fatty acylation of proteins: New insights into membrane targeting of myristoylated and palmitoylated proteins. Biochim Biophys Acta. 1451:1-16.

Rigden, J. E., Krake, L. R., Rezaian, M. A., and Dry, I. B. 1994. ORF C4 of tomato leaf curl geminivirus is a determinant of symptom severity. Virology 204:847-850

Robbins, S. M., Quintrell, N. A., Bishop, J. M. 1995. Myristoylation and differential palmitoylation of the HCK protein-tyrosine kinases govern their attachment to membranes and association with caveolae. Mol. Cell Biol. 15:3507-3515. 
Rutschmann, F., Stalder, U., Piotrowski, M., Oecking, C., Schaller, A. 2002. LeCPK1, a calcium-dependent protein kinase from tomato. Plasma membrane targeting and biochemical characterization. Plant Physiol. 129:156-168

Seal, S. F., Vandenbosch, A., Jeger, M. 2006. Factors influencing begomovirus evolution and their increasing global significance: Implications for sustainable control. 25:23-46

Simons, K., Ikonen, E. 1997. Functional rafts in cell membranes. Nature. 387:569-572.

Sung, Y. K., and Coutts, R. H. 1995. Pseudorecombination and complementation between potato yellow mosaic geminivirus and tomato golden mosaic geminivirus. J. Gen. Virol. 76:2809-15.

Te, J., Melcher, U., Howard, A., and Verchot-Lubicz, J. 2005. Soilborne wheat mosaic virus (SBWMV) $19 \mathrm{~K}$ protein belongs to a class of cysteine rich proteins that suppress RNA silencing. Virol J. 2:18-29.

Twyman, R. M., Stoger, E., Schillberg, S., Christou, P., and Fischer, R. 2003. Molecular farming in plants: Host system and expression technology. Trends Biotechnol. 21:570-578.

von Haller, P. D., Donohoe, S., Goodlett, D. R., Aebersold, R., and Watts,
J. D. 2001. Mass spectrometric characterization of proteins extracted from Jurkat T cell detergent-resistant membrane domains. Proteomics $1: 1010-1021$.

von Heijne,G., Steppuhn, J., and Herrmann, R. G. 1989. Domain Structure of mitochondrial and chloroplast targeting peptides. Eur. J. Biochem. 180:535-545.

Vanitharani, R., Chellappan, P., Pita, J. S., and Fauquet, C. M. 2004. Differential roles of $\mathrm{AC} 2$ and $\mathrm{AC} 4$ of cassava geminiviruses in mediating synergism and suppression of posttranscriptional gene silencing. J. Virol. 78:9487-9498

Voinnet, O., Pinto, Y. M., and Baulcombe, D. C. 1999. Suppression of gene silencing: A general strategy used by diverse DNA and RNA viruses of plants. Proc. Natl. Acad. Sci. U.S.A. 96:14147-14152.

Wang, J. K., Kiyokawa, E., Verdin, E., and Trono, D. 2000. The Nef protein of HIV-1 associates with rafts and primes $\mathrm{T}$ cells for activation. Proc. Natl. Acad. Sci. U.S.A.. 97:394-399.

Zamore, P. D., Tuschl, T., Sharp, P. A., and Bartel, D. P. 2000. RNAi: Double-stranded RNA directs the ATP-dependent cleavage of mRNA at 21 to 23 nucleotide intervals. Cell 101:25-33. 